\title{
The Influence of Tongue Cleaning Habit on the Occurrence of Adverse Halitosis Outcomes: A Review of Literature on the Current Evidence
}

\author{
Maj (Dr) Pamil Banotra*, Col (Dr) T Prasanth**, Lt Col (Dr) Manab Kosala**, Brig SK Bhandari, ** Surg Lt \\ Cdr (Dr) Goutam Nanavati** \\ ${ }^{1}$ Resident, ${ }^{2}$ Professor, ${ }^{3}$ Professor, ${ }^{4}$ Professor, ${ }^{5}$ Resident
}

*Division of Periodontology, *Dept of Dental Surgery and Oral Health Sciences, *Armed Forces Medical College, Pune, Pin411040, India

DOI: 10.29322/IJSRP.10.10.2020.p10670

http://dx.doi.org/10.29322/IJSRP.10.10.2020.p10670

\begin{abstract}
The purpose of this paper was to review the literature whether tongue cleaning needs to be a part of daily oral hygiene owing to presence of large number of microorganisms. Among the studies included for the present review, it has been observed that the occurrence of halitosis is reduced to a level of $75 \%$ after cleaning with mechanical tongue cleaning aids such as tongue scraper after 1 week. This is also confirmed by the organoleptic rating which suggests that there is significant reduction in the level of volatile sulphur compounds (VSCs) such as hydrogen sulfide, methyl mercaptan, dimethyl sulfide. This review aimed at to find out on existing literature regarding whether tongue cleaning is essential part of oral hygiene habit or not. It is evident that tongue forms the largest niche for microorganisms in the oral cavity and its association with halitosis, dental caries and plaque. On the basis of literature available it is recommended to clean the tongue regularly. Proper tongue brushing has found to be useful particularly when there is complaint of oral malodor.
\end{abstract}

Key words: Oral malodor, Halitosis, Bad breath, Fetor ex ore

\section{Introduction}

Tongue is one of the most anatomically important structure in mouth. Due to its location between the oral cavity and pharynx it provides passage to many different types of nutrients, products and bacteria [1]. The dorsum of tongue contains many papillae that provides a large surface area favouring the accumulation of oral debris and bacterias [2,3]. The microorganisms present on it may contribute to plaque formation [4]. These microorganisms comprise of up to $90 \%$ of the bacterial mass on the tongue. Gilmore and Bhaskar in there study found that the level of plaque-forming streptococci counts increases by tenfold after one week of not brushing the tongue [5]. It was recommended that tongue has to be cleaned daily in morning on an empty stomach to avoid vomiting or gagging [6].

Tongue hygiene has been routinely practiced till date by natives of Arabia, Africa, India, and South America. [7,8] whereas attention towards tongue cleaning is of little importance in western countries. Many ancient religions emphasized cleanliness of the entire mouth, including tongue. In these early cultures, oral cleansing often had religious ritual significance. Recently, tongue cleaning has received more attention because of the development of so called "Oral malodor" that can be considered as a social impediment. It has been studied that the food debris in the mouth contributes for up to 90 percent of oral malodor [9].

The tongue coating on posterior part of the dorsum of tongue comprises of millions of organisms. Tongue coating tends to vary in color and thickness. Normally, tongue is pink in color or has a thin white coating [10], and discoloured tongue is seen more likely in elderly because of change in dietary habits, decrease in salivary flow and their inability to cope with oral-hygiene methods [11]. The purpose of this paper was to review whether tongue cleaning needs to be a part of daily oral hygiene owing to presence of large no of microorganisms.

\section{Tongue coating}

The normal tongue coating is characterized by a thin, slightly moist, whitish substance, which is associated with the dorsal surface of the tongue. Tongue coating is comprised of dead epithelial cells, bacteria, blood end products, secretions from the postnasal area \& the gingiva, and saliva [12]. The filiform papillae of tongue because of its specific structure is involve in Tongue coating formation. Light and transmission electron microscopic studies on the Tongue coating revealed the presence of bacteria and exfoliated (desquamated) keratinized epithelium that originated from filiform papillae. Furthermore, filiform 
papillae, which assist in Tongue coating formation, were found to increase with age, and fungiform papillae decreased with age [15]. Entrapment of food remnants, saliva and microorganisms in filiform papillae leads to formation of thick coating [13].

As the age progresses Tongue coating becomes more thicker [14] and there is also variation in color, thickness, moisture and distribution depending on the patient's health. There is change in the color of Tongue coating after consuming substances including food like chocolates, drinks like coffee or black tea, and mouthwashes containing chlorhexidine and drugs [16]. There have been studies that indicate variations in thickness of Tongue coating depending on periodontal status and Halitosis. The Tongue coating thickness increases in patients suffering from periodontal disease, due to the migration of WBCs from periodontal pockets into the saliva, and subsequently, these cells are deposited onto the tongue surface [12] Gomez et al in his study found that Tongue coating was greater in periodontitis patients as compared to healthy individuals [14].

\section{Quantification of Tongue Coating}

Tongue coating has to be proper evaluated so as to motivate the patient in maintaining proper tongue hygiene. Tongue coating is quantified using visual parameters such as the coated area, Tongue coating discoloration and Tongue coating thickness (Table 1). Tongue coating can be quantified using alternative methods such as wet weight measurements of scrapings collected from the dorsum of tongue [12].

Table 1. The different types of tongue coating indices

\begin{tabular}{|c|c|c|}
\hline Authors & Score & Description \\
\hline \multirow[t]{4}{*}{ Gross et al (1975) } & 0 & No Coating \\
\hline & 1 & Slight Coating \\
\hline & 2 & Moderate Coating \\
\hline & 3 & Heavy Coating \\
\hline \multirow[t]{5}{*}{ Kojima et al (1985) } & 0 & No coating \\
\hline & 1 & Thin coating of $<1 / 3$ of the tongue \\
\hline & 2 & $\begin{array}{l}\text { Thin coating of }<2 / 3 \text { of the tongue or thick coating on } \\
<1 / 3 \text { of the tongue }\end{array}$ \\
\hline & 3 & $\begin{array}{l}\text { Thin coating of }>2 / 3 \text { of the tongue or thick coating on } \\
<2 / 3 \text { of the tongue }\end{array}$ \\
\hline & 4 & Thick coating of $>2 / 3$ of the tongue \\
\hline \multirow[t]{4}{*}{ Miyazaki et al. (1995) } & 0 & No coating \\
\hline & 1 & $<1 / 3$ Tongue dorsum surface covered \\
\hline & 2 & $<2 / 3$ Tongue dorsum surface covered \\
\hline & 3 & $>2 / 3$ Tongue dorsum surface covered \\
\hline \multirow[t]{10}{*}{ Mantilla Gomez (2001) } & Discoloration & \\
\hline & 0 & Pink \\
\hline & 1 & White \\
\hline & 2 & Yellow/Light Brown \\
\hline & 3 & Brown \\
\hline & 4 & Black \\
\hline & Thickness & \\
\hline & 0 & No Coating \\
\hline & 1 & Light-thin coating \\
\hline & 2 & Heavy-thick coating \\
\hline \multirow[t]{9}{*}{ Oho et al. (2001) } & Area & $\begin{array}{l}\text { Area score } \times \text { thickness score }=\text { tongue coating (range } 0 \text { - } \\
6 \text { ). }\end{array}$ \\
\hline & 0 & No tongue coating \\
\hline & 1 & $<1 / 3$ Tongue dorsum surface covered \\
\hline & 2 & $1 / 3-2 / 3$ Tongue dorsum is surface covered \\
\hline & 3 & $>2 / 3$ tongue dorsum surface covered \\
\hline & Thickness & \\
\hline & 0 & No coating \\
\hline & 1 & Thin tongue coating (papillae visible) \\
\hline & 2 & Thick tongue coating (papillae invisible) \\
\hline \multirow[t]{2}{*}{ Winkel et al. (2003) } & (Six areas grid) & $\begin{array}{l}\text { Tongue dorsum is divided into six areas (i.e. three } \\
\text { posterior and three anterior) }\end{array}$ \\
\hline & Coating & \\
\hline
\end{tabular}




\begin{tabular}{|l|c|l|}
\hline \multirow{7}{*}{} & 0 & No coating \\
\cline { 2 - 3 } & 1 & Light coating \\
\cline { 2 - 3 } & 2 & Severe coating \\
\cline { 2 - 3 } & Discoloration & \\
\cline { 2 - 3 } & 0 & No discoloration \\
\cline { 2 - 3 } & 1 & Light discoloration \\
\cline { 2 - 3 } Kim et al. (2009) & 2 & Severe discoloration \\
\hline & $\begin{array}{c}\text { Tongue coating } \\
\text { area }\end{array}$ & $\begin{array}{l}\text { Score is calculated by adding all six scores (range 0-12) } \\
\text { tongue imaging system (DTIS) }\end{array}$ \\
\hline
\end{tabular}

\section{Relationship of Tongue coating and Oral Malodor}

The role of tongue coatings in the causation of bad breath has been extensively studied. Sulfur substrates are essential for VSC production. These substrates are produced naturally in the oral cavity from gingival fluid, crevicular fluid and saliva. Delanghe et al evaluated patients with halitosis and concluded that main cause of halitosis in $51 \%$ of patients was because of tongue coating, $17 \%$ as a result of gingivitis, $15 \%$ as result of periodontitis and $17 \%$ because of combinations [17].

Miyazaki et al examined 2672 individuals aged 18 to 64 years suffering from halitosis and found that tongue coating is the only cause in younger individuals whereas periodontal diseases together with tongue coating was mainly responsible for oral malodor in older individuals [18].

Morita and Wang studied the relationship between sulcular sulfides level and oral malodor in patients with periodontal disease and found that volume of tongue coating and the percentile of sites with bleeding upon probing were significantly associated with halitosis [19].

Yaegaki and Sanada did an extensive study on biochemical and clinical factors influencing oral malador in periodontal patients and found that the levels of disulfide increased in relation to the pocket depth, $60 \%$ of the VSC was produced from the tongue surface, and the amount of coating was four times greater in test group than in control subjects. It was suggested that it is not only the microorganisms that contribute to VSC but also Tongue coating is a factor enhancing the production of VSC in patients with periodontal disease [20].

Quiryen et al studied the effect of one stage full mouth disinfection on oral malodor and also microbial colonization on patient's tongue having periodontal disease. He observed that there was correlation between baseline organoleptic ratings and VSC scores with the presence of tongue coating [21].

\section{Microflora on the dorsum of tongue}

In the year 1996 Gordon and Gibbons were the first to identify anaerobic microorganisms residing on dorsal surface of the tongue. Tongue serves as a potential reservoir for variety of periodontopathic microorganisms and may possibly function as a nidus for these organisms [22]. Krasse found the distribution of Streptococci salivarius and other streptococci in mouth and concluded that a large proportion of Streptococci salivarius is present on tongue [23]. Various investigators concludes that tongue is the ultimate reservoir of many salivary microorganisms and in general influence the microflora of entire oral cavity.

P.gingivalis was detected in high numbers on the dorsum of tongue, tonsils, buccal mucosa, gingiva and other mucous membranes in patients suffering from periodontitis where as it was absent or low in no in healthy individuals [24] A.actinomycetocomitans has been detected in subgingival samples and tongue taken from patients suffering from juvenile periodontitis. Approx 55\% of A.actinomycetocomitans has been detected in samples taken from dorsum of tongue [25].

P. Intermedia isolated from oral mucous membranes and saliva was detected in $99 \%$ of tongue samples from young adult Indonesian population. $\mathrm{P}$ intermedia was also found in $80 \%$ of tongue samples isolated from western population [26]. P. melaninogenica, P. loecheii, P. denticola, Candida albicans, Odontomyces viscous, Oral spirochetes are found on the tongue of either periodontally healthy and diseased subjects and are considered as normal colonizers of oral cavity [27,28,29].

Dental caries is correlated with the presence of streptococcus mutans which is found in plaque and its presence in saliva is considered to influence and contribute to the presence of these microorganisms on the tongue [30,31]. When the number of Colony Forming Unit (CFU) in saliva increases, the number of CFU on tongue increases as well [31].

\section{Tongue brushing}


Tongue can be easily cleaned using tongue scrapers which are made of either plastic ribbon or stainless steel held in both hands and can be pulled down over the dorsal surface of tongue and removing the coating. Brushing is the most common and easy method of cleaning the tongue, provided that one can have a control on gag reflex.

Massler suggested that if tongue cleaning habit is practised from the beginning of tooth brushing, the easier it will be to control the gag reflex [32].

Arnim $\mathrm{S}$ et al stated that dental caries and periodontal disease can be prevented by advocating routine tongue cleaning [33].

Gilmore El, Gross A and Whitley R found that the level of streptococcus salivarius variant present in plaque is altered by a regimen of daily tongue brushing [34].

Jacobson SE did a study on 30 patients for two weeks and concluded that brushing of tongue and palate twice a day significantly reduce oral debris which in turn reduces the initial rate of plaque formation [35].

Gross A et al concluded that tongue brushing when used as adjunct with tooth brushing have drastically reduced the salivary levels of caries causing streptococcus mutans [36].

Vasilakis GJ et al found that daily cleaning of rat tongue results in reduced plaque scores in the mouth [37].

Axelsson $\mathrm{P}$ et al found the presence of high numbers of Streptococcus mutans on the dorsum of tongue after thorough scrapings and reduction in there number after tooth cleaning and tongue scraping and concluded that dorsum of tongue was an important reservoir for Streptococcus mutans [38].

Menon V and Coykendall AL estimated the levels of bacterial load streptococcal counts from the tongue of 22 volunteers before and after tongue scrapping. They concluded that tongue scraping may impart a feeling of cleanliness and health to its user but does not reduced the count of streptococci on the tongue [39].

Gulati MS and Gupta L conducted a study on 20 female patients for 16 days and found $61.44 \%$ reduction in plaque accumulation in subjects performing brushing of tongue and teeth as compared to subjects performing brushing of teeth alone [40].

Dawes $\mathrm{C}$ et al studied the outcome of four oral hygiene procedures which includes tongue scraping and brushing on the output of bacteria into human saliva and concluded that all four oral hygiene procedures have similar effects on bacterial outputs into saliva [41].

Quirynen $\mathrm{M}$ et al found that 2 weeks of tongue brushing and scrapping twice daily results in negligible reductions in aerobic and anaerobic bacteria on the tongue [42].

White GE and Armaleh MT in there study compared the efficacy of tongue scraping, listerine oral strip and saline as an adjunct to twice daily tooth brushing and found tongue scraping to be most effective in reducing the count of streptococci mutans levels [43].

Roldan S et al evaluated while treating halitosis patients using mechanical and pharmacological approach based on clinical and microbiological outcomes and conclude that it significantly affected the microbial composition in tongue coating, saliva, and subgingival microflora [44].

Rupesh et al evaluated the effects of both tongue scraping and tongue brushing on streptococcus mutans level in saliva of children and concluded that both the methods were equally effective in reducing bacterial counts [45].

Jacob et al evaluated the effects of tongue cleaning and tongue scraping on plaque and streptococcus mutans levels and concluded that it results in reducing streptocooci counts but there was no significant reduction in plaque level [46].

Ana Carolina et al evaluated a new technique referred as the $\mathrm{X}$ technique for tongue brushing and concluded that $\mathrm{X}$ technique reduces the bacterial counts as well as improves the organoleptic rating [47].

\section{Conclusion}

This review aimed at to find out on existing literature regarding whether tongue cleaning is required or not. It is evident that tongue forms the largest niche for microorganisms in the oral cavity and its association with halitosis, dental caries and plaque. On the basis of literature available it is justified to clean the tongue at least once a day. Tongue brushing on a regular basis has found to be fruitful particularly when there is complaint of oral malodor which have a great impact on the social impediment. 


\section{References}

1. Roldan S, Herrera D, Sanz M. Biofilms and the tongue: therapeutic approaches for the control of halitosis. Clin Oral Invest 2003; 7:189-187

2. Jacobson SE, Crawford JJ, McFall WR. Oral physiotherapy of the tongue and palate: relationship to plaque control. J Am Dent Assoc 1973; 87: 134-9.

3. Bosy A, Kulkarni GV, Rosenberg, McCulloch CAG. Relationship of oral malodor to periodontitis: evidence of independence in discrete subpopulations. J Periodontol 1994; 65: 37-4

4. Van der Velden U, Van Winckelhoff AJ, Abbas F, de Graaf J. The habitat of periodontopathic micro-organisms. J Clin Periodontol 1986; 13: 243-8.

5. Gilmore, E.L., and Bhaskar, S.N. Effect of tongue brushing on bacteria and plaque formed in vitro. J Periodontol 43:418 July 1972.

6. Sarrazin JJ. Tongue cleansing. Dent Pract Dent Rec 1920; 30: 599.

7. Bodecker, H.W.C. The physiologically clean mouth. Dent Cosmos 68:425 May 1926.

8. Choksey, K.M., (ed.). Dentistry in ancient India. Bombay, Ambalal Hiralal Patel, p 34, 1953.

9. Prinz H. Offensive breath: its causes and prevention. Dent Cosmos 1930; 72:700.

10. Chen Z. Brief history of tongue inspection. Chinese Med J 1987; 100:38-44.

11. Ralph WJ. Oral hygiene - why neglect the tongue? Aust Dent J 1988; 33: 224-5.

12. Yaegaki K and Sanada K 1992 Biochemical and clinical factors influencing 478 oral malodor in periodontal patients. J. Periodontol. 63 783-9

13. Huguley CM 1990 The Tongue, Clinical Methods: The History, Physical, and Laboratory Examinations third edition, Chapter 130 editors HK Walker, WD Hall and JW Hurst.

14. Gómez SM, Danser MM, Sipos PM, Rowshani B, Van Der Velden U and Van Der Weijden GA 2001 Tongue coating and salivary bacterial counts in healthy/gingivitis subjects and periodontitis patients; J. Clin. Periodontol. 28 970-8

15. Danser MM, Gómez SM, Van der Weijden 2003 Tongue coating and tongue brushing: a literature review Int. J. Dent. Hyg. 1 151

16. Amir KA, Bobba RK, Clarke B, Nagy-Agren S, Arsura EL, Balogun SA and Evans JM 2006 Tongue discoloration in an elderly kidney transplant recipient: Treatment-related adverse event? Am. J. Geriatr. Pharmacother. 4 260-3

17. Delanghe G, Bollen C, Van Steenberghe D, Feenstra L. Multidisciplinaire aanpak van halitosis. Ned Tijdscr Tandheelk 1998; 105: 314-7.

18. Miyazaki H, Sakao S, Katoh Y, Takehara T. Correlation between volatile sulphur compounds and certain oral health measurements in the general population. J Periodontol 1995; 66: 679-84.

19. Morita M, Wang H-L. Association between oral malodor and adult periodontitis. J Clin Periodontol 2001; 28: 813-9.

20. Yaegaki K, Sanada K. Volatile sulfur compounds in mouth air from clinically healthy subjects and patients with periodontal disease. J Periodont Res 1992; 27: 233-8.

21. Quirynen M, Mongardini C, Van Steenberghe D. The effect of a 1-stage full-mouth disinfection on oral malodor and microbial colonization of the tongue in periodontitis patients. A pilot study. J Periodontol 1998; 69: 374-82. 
22. Van der Velden U, Van Winckelhoff AJ, Abbas F, de Graaf J. The habitat of periodontopatic micro-organisms. J Clin Periodontol 1986; 13: 243-8.

23. Krasse B. The proportional distribution of Streptococcus salivarius and other streptococci in various parts of the mouth. Odontologisk Revy 1954; 5: 203-11.

24. Griffen AL, Becker MR, Lyons SR, Moeschberger ML, Leys EJ. Prevalence of Porphyromonas gingivalis and periodontal health status. J Clin Microbiol 1998; 36: 3239-42.

25. Asikainen S, Alaluusua S, Saxe'n L. Recovery of Actinobacillus actinomycetemcomitans from teeth, tongue and saliva. J Periodontol 1991; 62: 203-6.

26. Lie MA, Van der Weijden GA, Timmerman MF, Loos BG, Van Steenbergen TJM, Van der Velden U. Oral microbiota in smokers and non-smokers in natural and experimentally induced gingivitis.

J Clin Periodontol 1998; 25: 677-86.24.

27. Van Steenbergen TJ, Van der Velden U, Abbas F, De Graaf J. Microbiological and clinical monitoring of non-localized juvenile periodontitis in young adults: a report of 11 cases. J Periodontol

1993; 63: 40-7.

28. Dzink JL, Tanner ACR, Haffajee AD, Socransky SS. Gram-negative species associated with active destructive periodontal lesions. J Clin Periodontol 1985; 12: 648.

29. Dahle'n G, Manji F, Baelum V, Fejerskov O. Putative periodontopathogens in 'diseased' and 'non-diseased' persons exhibiting poor oral hygiene. J Clin Periodontol 1992; 19: 35-42.

30. Togelius J, Kristofferson K, Anderson H, Bratthall D. Streptococcus mutans in saliva: intraindividual variations and relation to the number of colonized sites. Acta Odontologica Scand 1984; 42: 157-63.

31. Lindquist B, Emilson CG, Wennerholm K. Relationship between mutans streptococci in saliva and their colonization of the tooth surfaces. Oral Microbiol Immunol 1989; 4: 71-6.

32. Ralph WJ. Hygiene of the tongue. Gerodontics 1987; 3: 169-70.

33. Arnim S, Diercks CC and Pearson EA Jr. What you need to know and do to prevent dental caries and periodontal disease. J NC Dent Soc 1963; 46: 296.

34. Gilmore EL and Gross A. Effect of tongue brushing on plaque bacteria. Oral Surg Oral Med Oral Pathol 1973; 39 : 893-895.

35. Jacobson SE, Crawford JJ and Mc Fall WR Jr. Oral physiotherapy of the tongue and palate: relationship to plaque control. J Am Dent Assoc July 1973; 87: 134-139.

36. Gross A, Barnes GP and Lyon TC. Effects of tongue brushing on tongue coating and dental plaque scores. J Dent Res 1975; 54: 1236.

37. Vasilakis GJ, Preis CO, Glaz J and Bissada NF. Effects of daily mechanical tongue cleaning of the rat on dental plaque and tongue mucosa. J Clin Prev Dent 1985; 3(5): 7-10.

38. Axelsson P, Kristofferson K, Karlsson R and Bratthall D. A 30-month longitudinal study of the effects of some oral hygiene measures on streptococcus mutans and approximal dental caries. J Dent Res 1987; 66: 761-765.

39. Menon MV and Coykendall AL. Effect of tongue scraping. J Dent Res 1995; 73: 1492.

40. Gulati MS and Gupta L. Clinical evaluation of supplementary tongue brushing to the most advocated regime of tooth brushing. J Ind Soc Pedod Prev Dent Mar 1998; 16: 12-16.

41. Dawes C, Tsang RW and Suelzle T. The effects of gum chewing, four oral hygiene procedures, and two saliva collection techniques, on the output of bacteria into human whole saliva. Arch Oral Biol 2001 Jul; 46(7): 625-32.

42. Quirynen M, Avontroodt P, Soers C, Zhao H, Pauwels M and Van Steenberghe D. Impact of tongue cleansers on microbial load and taste. J Clin Periodontol 2004; 31: 506-510. 
43. White GE and Armaleh MT. Tongue scrapping as a means of reducing oral mutans streptococci. J Clin Pediatr Dent 2004; 28(2): 163-166.

44. Roldan S, Herrera D, O'connor A, Gonzalez I and Sanz MA. Combined therapeutic approach to manage oral halitosis: a 3month prospective case series. J Periodontol 2005 Jun; 76(6): 1025-1033.

45. Rupesh S, Winnier JJ, Nayak UA, Rao A, Reddy V, Peter J. The comparative evaluation of the effects of tongue cleaning on salivary levels of mutans streptococci in children. Int J Dent Hyg 2012 May;10(2). 107-112

46. Jacob KC, Yashoda R, Puranik MP, Bano A. Effects of tongue cleaning on plaque and salivary mutans streptococci levels: A randomized control trial. J Indian Assoc Public Health Dent 2015; 13:378-83

47. Gonçalves ACS, Martins MCN, Paula BL, Weckwerth PH, Franzolin SOB, Silveira EMV. A new technique for tongue brushing and halitosis reduction: the X technique. J Appl Oral Sci. 2019 Apr 1;27:e20180331

\section{Authors}

First Author - Maj (Dr) Pamil Banotra, Resident Periodontology, Armed Forces medical college, Pune. drpami11984@gmail.com

Second author - Col (Dr) T Prasanth, Professor [Periodontology], Armed forces medical college, Pune. prasanthavin@gmail.com

Third Author- Lt Col (Dr) Manab Kosala, Professor [Periodontology], Armed Forces medical college, Pune.

kosalamanab@hotmail.com

Fourth Author- Brig (Dr) SK Bhandari, Professor \& HOD Dept of dental surgery and health sciences , Armed forces medical college, Pune. kumarsdel@gmail.com

Fifth Author- Surg Lt Cdr (Dr) Goutam Nanavati, Resident Periodontology, Armed Forces medical college, Pune. goomsy@gmail.com

\section{Correspondence Author-}

Col (Dr) T Prasanth, Professor [Periodontology], Armed forces medical college, Pune. pamil1983honey@yahoo.co.in, Mobile no - 08284851155 